\title{
Validity of the Capital Asset Pricing Model (CAPM) for Securities Trading at the Nairobi Securities Exchange (NSE)
}

\author{
Georgas Janata ${ }^{1}$ \\ ${ }^{1}$ School of Business, University of Nairobi, Kenya \\ Correspondence: Georgas Janata, School of Business, University of Nairobi, Kenya \\ Received: September 9, 2016 \\ Accepted: December 16, 2016 \\ Online Published: December 19, 2016 \\ doi:10.5430/bmr.v5n4p62 \\ URL: http://dx.doi.org/10.5430/bmr.v5n4p62
}

\begin{abstract}
This research undertakes an empirical analysis of the validity of the Capital Asset Pricing Model (CAPM) for securities trading at the Nairobi Securities Exchange (NSE). Based on the critical conditions of the CAPM model, the specific objectives of the research were: to evaluate the level of systematic risks for firms listed on the NSE, to evaluate the rate of return for individual stocks listed on the NSE, to evaluate the rate of return for the NSE, to analyze the relationship between systematic risk and expected returns for firms listed on the NSE, and to evaluate the value of the intercept term for firms listed on the NSE.

Fama \& Macbeth's two-pass regression method is applied to a sample of eighteen firms trading at the NSE, with the most recent data (May 2013 -May 2016) being used. By virtue of finding a beta value that is statistically different from zero, the study concludes that the CAPM is not a valid model for explaining risk-return relationships at the NSE. Other critical conditions which the findings violate include: the hypothesized linear risk-return relationship, and the hypothesized zero value for the intercept. Some of the failures of the CAPM are attributed to its theoretical failings, and specifically, its many unrealistic and simplifying assumptions.

Although this study addresses the methodological weaknesses of prior studies by basing analysis on portfolios rather than individual stocks (thus correcting measurement error problems) and carrying out month-by-month cross-section regression (thus correcting residual errors); the methodology adopted still fails to account for anomalies in asset pricing. Therefore, in addition to recommending that future studies adopt methodologies that account for pricing anomalies, this study also recommends that future studies consider expanding the number of firms to study as well as the period of study. This can help to generate more observations, and therefore, better data fit.
\end{abstract}

Keywords: CAPM, Nairobi Securities Exchange, Beta, Risk, Returns

\section{Introduction}

Optimization of financial investment decisions usually requires investors to achieve the most appropriate trade-off between risk and returns. Ideally, the most optimal portfolios is one where the highest possible returns are obtained at the lowest possible risk level (the risk-free rate of return, proxied by long-term government securities) (Brigham, \& Houston, 2015). Arriving at such an optimal trade-off position is, however dilemmatic for most investors, given that risks and returns for any investment decision are always positively correlated (Baker \& Riddick, 2013).

One of the most popular empirical models used to resolve this risk-return dilemma is the Capital Asset Pricing Model (CAPM) (Sharifzadeh, 2010). Originally developed by Sharpe (1964) and Lintner (1965), the CAPM model is considered superior to other models due to various reasons. Firstly, it generates more reliable discount rates for investment appraisal purposes compared to the Weighted Average Cost of Capital (WACC). Secondly, contrasting with Markowitz's portfolio theory, it incorporates both systematic and specific risks in its analysis. Unlike the dividend growth model, it considers the firm's systematic risk levels vi's-à-vi's the entire stock market, and is therefore seen as a more superior method for computing the cost of equity (Baker \& Riddick, 2013). Moreover, and perhaps most important for financial investment decisions, it provides a framework through which the theoretical nexus between expected returns and systematic risks can be derived (Brigham, \& Houston, 2015).

This nexus between systematic risk and expected return has been the subject of many empirical studies. However, the findings generated from these studies remain inconsistent and mixed (Bhala, Yeh, \&Bhala, 2016). For the validity of the CAPM model to be affirmed, its critical conditions have to be satisfied. These include: a positive and linear risk-return correlation, significance of market risk as an explanatory variable of the given security's risk 
premium, and a zero value for the intercept term (Brigham \& Houston, 2015). While some studies have adduced findings, which support these critical conditions and therefore affirm the validity of the CAPM model (e. g. Heshmat, 2012; Köseoğlu \& Mercangoz, 2013), others have generated findings, which reject these conditions, and therefore reject the validity of the CAPM model (e. g. Nyangara et al., 2016; Fama \& French, 2004). Other studies have found evidence to accept some of these conditions, while rejecting others (e. g. Pamane \& Vikpossi, 2014;Maitah et al, 2015), or found evidence to only support the limited applicability of the model (e.g. Khan et al, 2012).

Yet, a number of other studies have called into question the validity of the model, based on its unrealistic assumptions, which include: the assumptions of perfect capital markets, zero transaction costs, rational investors, and risk-free borrowing rate (e. g. Elbannan, 2015; Fama \& French, 2004). However, others point to the high utility of the model, almost six decades after it was first formulated, based on its simplicity and high level of clarity, and the inability of alternative models to adequately match it (e.g. Nyangara et al, 2016).

The inconsistent and mixed findings aside, Pamane \& Vikpossi (2014) have also pointed out that even though very many studies have been carried out regarding the validity of the CAPM model, most of the studies have focused on the financial markets of the industrialized countries, and that studies on the emerging or less developed countries are very limited. This observation has also found support from Hearn \& Piesse (2009) and Okumu \& Onyuma (2015).

Nevertheless, a few studies focusing on the Kenyan context have been carried out. These include Okumu \& Onyuma (2015), Hearn \& Piesse (2009), and Coffie \& Chukwulobelu (2013). However; these studies also suffer from a number of methodological weaknesses, and as such are characterized by measurement error and residual problems.

With this background therefore, this research focuses on the analysis of the validity of the CAPM model, with a specific focus on the Nairobi Securities Market (NSE). Based in Kenya, the NSE is the largest stock exchange in East Africa. It was formally established in 1954, and has 65 firms listed across all the segments in the market (NSE, 2016).

\section{Research Objectives}

The researcher's key remit is to analyze the validity of the capital asset pricing model (CAPM), with a specific focus on the Nairobi Securities Exchange. Accordingly, the following specific objectives, based on the critical conditions of the CAPM model, were adopted for the research study:

1. To evaluate the level of systematic risks for firms listed on the NSE

2. To evaluate the levels of rates of returns for firms listed on the NSE

3. To evaluate the levels of market returns for the NSE

4. To analyze how expected returns fluctuate in response to shifts in the systematic risk for firms listed on the NSE

5. To evaluate the value of the intercept term for firms listed on the NSE

\section{Significance of the Study}

This research study is justified on the grounds that it addresses the observed research gap in a unique way. Firstly, unlike the predominant approach of focussing on individual stocks adopted by prior studies which have focused on the NSE, this research adopts the Fama \& Macbeth methodology, where the analysis is based on portfolios rather than individual securities. Secondly, it uses cross-sectional month-by-month regressions in the second pass regression. This methodological approach is useful in avoiding the residual and measurement error problems present in the previous studies which have focused on the Kenyan context. This research study also uses a larger set of firms, more recent data (May 2013-May 2016), and a longer study period. A majority of the studies have focused on the industrialized countries. The few studies focussing on Kenya suffer from some methodological limitations, which include: measurement error and residual problems. Moreover, some of the studies are fairly old (i.e. use of relatively out-dated datasets), and are based on relatively very short analysis periods of just one year. In addition to these reasons, CAPM studies focussing on the NSE are relatively few. Given the fact that the NSE is one of the largest bourses in Africa, therefore, this study becomes imperative to undertake (Okumu \& Onyuma, 2015).

\section{Empirical Review of the CAPM}

Numerous empirical studies have been carried out with the intention of assessing the validity of the CAPM model. Although some of the studies have established strong empirical support for the model, others have provided evidence which basically invalidates the model. Yet others have established limited support for the model (Bhala, Yeh, \& Bhala, 2016). 
Although CAPM studies within the Kenyan context are limited, one of the notable studies which have been carried out is that of Coffie \& Chukwulobelu (2013). Using the time-series regression, the researchers demonstrated that the CAPM was an adequate model which satisfactorily accounted for the risk-return relationships in the country. However, the researchers also noted that even though the beta significantly explained stock returns, it was not the sole determinant of expected returns. Other variables, which are not captured by the model, equally contributed to the observed returns.

A significant methodological weakness of the research by Coffie \& Chukwulobelu (2013) however, is that, the analysis was based on data for individual securities rather than portfolios. As pointed out by Fama \& French (2004), one of the problems associated with the tests for CAPM is the imprecise measurement of beta when it is used to account for expected returns, which in turn leads to the measurement error problems. In view of this, it has become standard practice for researchers to use portfolios rather than individual securities, since diversified portfolios enhance preciseness and reduce the measurement errors. Consequently, the study by Coffie \& Chukwulobelu (2013) suffers from critical methodological weaknesses which may have affected the validity of its findings.

In another study focussed on the Kenyan context, Okumu \& Onyuma (2015) computed the risk-return relationship for sixteen stocks trading under various categories/sectors in the NSE 20 share index for the year 2010. Using regression analysis, the researchers demonstrated an extremely weak (but positive) correlation and coefficients of determination between the evaluated securities' beta and the market returns, leading to the conclusion that the CAPM is not a valid predictor of the risk-return relationship for securities trading in the Kenyan stock market.

Like the previous study of Coffie \& Chukwulobelu (2013), Okumu \& Onyuma (2015) made no attempt to reduce measurement error problems through the use of portfolios rather than individual securities. Even though their findings contradicted the findings made by Coffie \& Chukwulobelu (2013), it still suffered from the same methodological weaknesses present in Coffie \& Chukwulobelu (2013).

In their study of the validity of the CAPM model for four African countries (Kenya included), Hearn \& Piesse (2009) adopted a methodology which avoided some of the key methodological limitations associated with the much later studies of Coffie \& Chukwulobelu (2013) and Okumu \& Onyuma (2015).They modified the Fama \& French three-factor model (Fama \& French, 1993) by incorporating size and liquidity effects. Although their study minimized measurement error problems through the use of portfolios, Fama \& French (2004) state that the use of portfolios introduces an additional problem of beta shrinkage and reduction of statistical power. By sorting their portfolios based on size and liquidity, Hearn \& Piesse (2009) were able to minimize this problem. However, the use of a single regression still means that this study suffered from the problem of residuals. The researchers established that the augmented CAPM model was a better predictor of the cost of equity compare to the Sharpe-Lintner version of the CAPM, with the cost of equity, among the markets sampled, being highest in Kenya.

Apart from the problem of measurement errors, Fama \& French (2004) have also pointed out that the use of regression analysis in the assessment of the validity of CAPM is often associated with residuals, where a positive correlation exerts a downward bias in the estimation of standard errors of the regression slope. Although this is a weakness that can be corrected by undertaking a month-by-month regression instead of a single regression, both the studies of Coffie \& Chukwulobelu (2013) and Okumu \& Onyuma (2015) fail to correct for this residual problem, and their findings are therefore likely to have been affected by bias. Although Okumu \& Onyuma (2015) use more recent data compared to Hearn \&Piesse (2009) and Coffie \& Chukwulobelu (2013), their study is based on a very short period of analysis (12 month sample period).

Methodological weaknesses aside, a number of empirical studies have also found fault with the theoretical failings of the CAPM model, based on its many unrealistic assumptions. For example, the assumptions of investor rationality and homogeneous investor expectations have been challenged by empirical studies which validate the significance of noise traders in financial markets (De Long et al., 1990). Markowitz (2005) challenged the assumption of zero transaction costs by pointing at the presence of broker fees, taxes, and interest.

\section{Research Methods}

\subsection{Research Variables and Proxy Measures}

The key research variables included risk and market return. In line with the standard approach adopted in the CAPM literature, beta was used as the proxy measure for specific risk, while the NSE all-share index (NASI) was used as the proxy measure for market return. 


\subsection{Data Sources and Sampling}

The beta (for 58 firms), risk-free rate, and market return data were collected from secondary data sources (NSE, 2016). This data was for the period May 2013-May 2016, and was collected from secondary sources which included: annual reports of the sampled firms, online financial portals, and the NSE website.

\subsection{Research Procedures}

Fama \& Macbeth's methodology, which involves a two-pass regression procedure, was utilized. Since regression analysis is based on a series of assumptions; the normality of the data collected was initially assessed via the K-S test. Homoscedasticity was assessed using the Levene statistic), autocorrelation using the Durbin-Watson test, and multicollinearity using the variation inflation factor or VIF test. Since $n>50$, normality was tested statistically using the Kolmogorov-Smirnov test.

The first step of the analysis involved the estimation of betas for the individual stocks. This was obtained by regressing the stock returns of the various securities (ri) against the market returns (rm), for the year May 2013-April 2016. The beta $(\beta)$ is equivalent to the slope of the regression line, represented by the equation: $\mathrm{r}=\alpha+\beta \mathrm{rm}$, with $\alpha$ denoting the intercept. A confidence interval of 0.05 was used.

The second step involved ranking the various stocks at the NSE into portfolios, based on the betas estimated in step 1 above. Three portfolios, with six stocks each, were formed, with the first portfolio consisting of firms having the lowest betas, the second consisting of firms having the second lowest betas, and so on, up to the sixth portfolio which consisted of firms with the highest beta values.

In the third step, monthly returns for the portfolios for the year May 2014-April 2015 were estimated based on weighted averages. Portfolio betas for the year May 2014-April 2015 were also estimated, by regressing the monthly returns against the market returns. Use of portfolios was helpful in addressing the methodological weaknesses of imprecise measurement, as well as the problem of shrinkage of beta ranges.

Cross-sectional regressions of the portfolio returns and betas were then run, using portfolio returns for the period May 2015-April 2016 and the portfolio betas estimated in the previous step. Use of month-by-month cross-section regression was useful in helping to address the methodological problem of residuals inherent in earlier studies.

The time series of means of the slopes and intercepts were then used to assess if the mean beta premium is positive or if the average return on the stocks which are uncorrelated to the market are equal to the mean risk-free rate.

\section{Data Analysis}

\subsection{Data Diagnostics}

At a significance level of $95 \%$, K-S tests show that the distribution of all the 58 active stocks evaluated is normal (i.e. $\mathrm{p}>0.05$ ) for only 26 of the stocks, as well as for the NASI distribution, but is non-normal for thirty of the stocks (table 1 below). 


\begin{tabular}{|c|c|c|c|}
\hline Stock/Index & KS test (sig) & Stock/Index & KS test (sig) \\
\hline Kapchorua Tea & 0.013 & Pan Africa Insurance Holdings & 0.001 \\
\hline Longhorn Kenya & 0.001 & Trans-Century & $0.104 *$ \\
\hline Williamson Tea & 0.000 & KPLC & $0.102 *$ \\
\hline Marshalls (E.A.) & 0.003 & Safaricom & $0.200^{*}$ \\
\hline Eaagads Ltd & 0.031 & Total Kenya & 0.005 \\
\hline Sasini Ltd & $0.070^{*}$ & NBK & 0.003 \\
\hline Mumias Sugar & 0.000 & Equity Bank & $0.200^{*}$ \\
\hline Kakuzi & 0.021 & Uchumi & $0.086^{*}$ \\
\hline Express Ltd & 0.005 & Co-op Bank & $0.200 *$ \\
\hline Eveready & 0.021 & Kenya Re & $0.200^{*}$ \\
\hline BRITAM & 0.008 & Carbacid Investments & 0.000 \\
\hline TPS E.A (Serena) & $0.200^{*}$ & NMG & $0.090^{*}$ \\
\hline Bamburi Cement & $0.069^{*}$ & Scangroup & $0.127^{*}$ \\
\hline KenolKobil & $0.200^{*}$ & StanChart & 0.036 \\
\hline B.O.C Kenya & $0.113^{*}$ & BAT & 0.013 \\
\hline DTB & $0.200 *$ & Housing Finance & $0.167 *$ \\
\hline Unga Group & $0.200 *$ & BBK & $0.200^{*}$ \\
\hline Olympia Capital Holdings & 0.021 & $\mathrm{KCB}$ & $0.086^{*}$ \\
\hline Standard Group & 0.034 & NIC Bank Ltd & $0.200^{*}$ \\
\hline E.A. Cables & 0.026 & Centum & $0.200^{*}$ \\
\hline Kenya Airways & 0.002 & Liberty Kenya Holdings & $0.051^{*}$ \\
\hline E.A.P.C & $0.200 *$ & Kenya Orchards & 0.000 \\
\hline Car and General & 0.032 & KenGen & $0.200 *$ \\
\hline Sameer Africa & $0.200^{*}$ & ARM & $0.192 *$ \\
\hline EABL & 0.025 & CIC Insurance Group & 0.004 \\
\hline Jubilee Holdings & 0.005 & NASI & 0.200 \\
\hline CFC Stanbic Holdings & 0.001 & Crown Berger & 0.001 \\
\hline I\&M Holdings & 0.005 & & \\
\hline
\end{tabular}

*Non-normal

The normality of market returns was also tested and is given in the table 2 below:

Table 2. Normality test for the NASI Returns Data

\begin{tabular}{lcccccc}
\hline \multicolumn{4}{c}{ Kolmogorov-Smirnov $^{\text {a }}$} & \multicolumn{3}{c}{ Shapiro-Wilk } \\
\hline \multirow{3}{*}{ NASI } & Statistic & df & Sig. & Statistic & df & Sig \\
& .093 & 36 & $.200^{*}$ & .939 & 36 & 0.47 \\
\hline
\end{tabular}

The K-S test shows that the $\mathrm{p}$ value (i.e. 0.2)>0.05. Therefore, the research concludes that the distribution of the market returns data is normal. The data for the 26 stocks satisfying the normality assumption, as well as for the market returns, was also tested for multicollinearity (using the VIF test), homoscedasticity (using the Levene statistic), autocorrelation (using the Durbin-Watson test), and linearity (using scatterplots).

The summary of the outputs of the homoscedasticity test is given in table 3 below: 
Table 3. Homoscedasticity Test

\begin{tabular}{lcccccr}
\hline ANOVA & \multicolumn{7}{l}{ MS } & $F$ & P-value & F crit \\
\hline Source of Variation & $S S$ & $d f$ & 0.010803079 & 1.468889804 & 0.065002 & 1.518221 \\
Between Groups & 0.270076969 & 25 & 0.01 & & \\
Within Groups & 6.692674729 & 910 & 0.007354588 & & & \\
Total & 6.962751697 & 935 & & & &
\end{tabular}

Source: author

From table 3 above, the $p$-value is $0.06>0.05=\alpha$. Consequently, we fail to reject the null hypothesis, and instead affirm that no significant difference exists between the means of groups of stocks. Therefore, the groups of stocks used to satisfy the assumption of homogenous variances. The summary of the outputs for the other diagnostics (Durbin Watson and VIF tests) is given in table 4 below:

Table 4. Multicollinearity and autocorrelation test outputs

\begin{tabular}{lccccc}
\hline Stock & VIF & D-W & Stock & VIF & D-W \\
\hline Sasini & 1.000 & 2.462 & Uchumi & 1.000 & 2.079 \\
TPS & 1.000 & 2.281 & Co-op Bank & 1.000 & 2.643 \\
Bamburi & 1.000 & 2.215 & Kenya Re & 1.000 & 1.618 \\
KenolKobil & 1.000 & 2.455 & NMG & 1.000 & 1.691 \\
B.O.C & 1.000 & 2.114 & Scangroup & 1.000 & 2.341 \\
DTB & 1.000 & 2.067 & HFCK & 1.000 & 1.638 \\
Unga & 1.000 & 2.013 & BBK & 1.000 & 2.566 \\
E.A. P.C & 1.000 & 1.686 & KCB & 1.000 & 2.344 \\
Sameer & 1.000 & 2.431 & NIC & 1.000 & 2.284 \\
Trans-Century & 1.000 & 1.619 & Centum & 1.000 & 1.951 \\
KPLC & 1.000 & 2.630 & Liberty & 1.000 & 2.642 \\
Safaricom & 1.000 & 1.794 & KenGen & 1.000 & 2.569 \\
Equity Bank & 1.000 & 1.599 & ARM & 1.000 & 2.199 \\
\hline
\end{tabular}

Source: author

From table 3 above, all the VIF values are1.0. The rule of thumb is to accept any VIF value less than 4, and so we conclude that the data is free of multicollinearity. From table 4-3above, it is also evident that the D-W values for all the stocks range between 1.6 and 2.6. Since these values are closer to 2 than they are to either 4 (i.e. negative autocorrelation) or 0 (i.e. positive correlation), the research concludes that the data has no autocorrelation. In summary, the data for the 26 stocks and market returns satisfy all the assumptions of parametric tests, and as such, regression analysis based on the Fama \& Macbeth methodology can be applied.

\subsection{Calculation of Beta Values}

Time series regression analysis between the individual stock and market returns are run for the period June 2013-May 2014 to establish the betas for the 26 stocks. These are run based on the regression equation below:

$r_{i}=\alpha+\beta_{1} r_{m 1}+\beta_{2} r_{m 2} \ldots+\beta_{26} r_{m 26}$, where ri is the stock return, $\beta$ is the beta (the slope of the regression line), $r_{m}$ is the market returns, and $\alpha$ is the $y$ intercept.

The coefficient of determination (i.e. R square) of this model is $97.9 \%$, indicating a strong predictive ability of the model. At a confidence level of $95 \%$, the significance value is 0.000 , indicating that the findings are significant. The results for the individual stocks are shown below: 
Table 5. Time Series Regression for Stock-Market Returns (Beta)

\begin{tabular}{lccccccc}
\hline Stock & $\boldsymbol{\alpha}$ & $\boldsymbol{\beta}$ & Sig. & Stock & $\boldsymbol{\alpha}$ & $\boldsymbol{\beta}$ & Sig. \\
\hline Sasini & 0.005 & 0.027 & $0.876^{*}$ & Uchumi & 0.007 & 0.144 & $0.401^{*}$ \\
TPS & 0.008 & 0.242 & $0.155^{*}$ & Co-op Bank & 0.001 & 0.639 & $0.000^{* *}$ \\
Bamburi & 0.005 & 0.132 & $0.443^{*}$ & Kenya Re & 0.003 & 0.477 & $0.003^{* *}$ \\
KenolKobil & 0.004 & 0.403 & $0.015^{* *}$ & NMG & 0.009 & 0.445 & $0.007^{* *}$ \\
B.O.C & 0.005 & 0.176 & $0.304^{*}$ & Scangroup & 0.010 & 0.549 & $0.001^{* *}$ \\
DTB & 0.002 & 0.422 & $0.010^{* *}$ & HFCK & 0.005 & 0.666 & $0.000^{* *}$ \\
Unga & -0.002 & 0.505 & $0.002^{* *}$ & BBK & 0.011 & 0.607 & $0.000^{* *}$ \\
E.A. P.C & 0.007 & 0.400 & $0.016^{* *}$ & KCB & 0.004 & 0.794 & $0.000^{* *}$ \\
Sameer & 0.006 & 0.292 & $0.084^{*}$ & NIC & 0.007 & 0.656 & $0.000^{* *}$ \\
Trans-Century & 0.001 & -0.179 & $0.297^{*}$ & Centum & -0.002 & 0.632 & $0.000^{* *}$ \\
KPLC & 0.007 & 0.380 & $0.022^{* *}$ & Liberty & 0.004 & 0.304 & $0.072^{*}$ \\
Safaricom & -0.009 & 0.841 & $0.000^{* *}$ & KenGen & 0.007 & 0.367 & $0.028^{* *}$ \\
Equity Bank & 0.003 & 0.645 & $0.000^{* *}$ & ARM & 0.007 & 0.511 & $0.01^{* *}$ \\
\hline
\end{tabular}

*not significant at the 0.05 level; **significant at the 0.05 level

Source: author.

Evident from table 5 above, the findings of eight of the stocks (i.e. Sasini, TPS Serena, Bamburi, B.O.C., Sameer, Uchumi, Liberty, and Trans-Century) are not significant (i.e. $p>0.05$ ), and these are omitted from further analysis. Therefore, subsequent analysis focuses on the remaining 18 stocks.

Analysis of the stocks shows that the beta value for all the eighteen stocks whose stock return-market return relationship findings are significant, are less than 1.0. This indicates that all these stocks are less volatile than the market. By virtue of this, they are considered low-risk, and therefore, are potentially associated with lower returns.

\subsection{Portfolio Ranking, Returns, and Beta Values}

In line with the standard approach, the eighteen stocks were ranked and sorted (by beta, from smallest to highest), and then grouped into three portfolios of 6 firms each, as shown in table 6 below:

Table 6. Portfolio Sorting and Ranking

\begin{tabular}{|c|c|c|c|c|c|c|c|c|}
\hline \multicolumn{3}{|c|}{ Portfolio 1} & \multicolumn{3}{|c|}{ Portfolio 2} & \multicolumn{3}{|c|}{ Portfolio 3} \\
\hline Rank & Stock & Beta & Rank & Stock & Beta & Rank & Stock & Beta \\
\hline 1 & KenGen & 0.367 & 7 & Kenya Re & 0.477 & 13 & Co-op Bank & 0.639 \\
\hline 2 & KPLC & 0.38 & 8 & Unga & 0.505 & 14 & Equity Bank & 0.645 \\
\hline 3 & E.A. P.C & 0.4 & 9 & ARM & 0.511 & 15 & NIC & 0.656 \\
\hline 4 & KenolKobi & 0.403 & 10 & Scangroup & 0.549 & 16 & HFCK & 0.666 \\
\hline 5 & DTB & 0.422 & 11 & BBK & 0.607 & 17 & $\mathrm{KCB}$ & 0.794 \\
\hline 6 & NMG & 0.445 & 12 & Centum & 0.632 & 18 & Safaricom & 0.841 \\
\hline
\end{tabular}

Source: author

The monthly returns of the above six portfolios, for the period between June 2014 and May 2015 were then estimated from the monthly returns of the individual stocks which make up each portfolio, using the formula:

$$
\mathrm{E}(\mathrm{R})=\sum_{i=1}^{n} \mathrm{PixRi}
$$

This formula can also be expressed differently, as: ${ }_{1} R_{1}+w_{2} R_{q}+\ldots+w_{n} R_{n}$, where $W$ is the weighted average of each stock in the portfolio (with the weights assigned based on the number of issue shares on the NSE, table 7 
below), and $\mathrm{R}$ is the return of each stock in the portfolio. The number of issued shares for each stock is used as the weight factor, and the results are given in table 8 below.

Table 7. Weight Factors - Number of Issued Shares

\begin{tabular}{lrlr}
\hline Stock & No. of shares & \multicolumn{1}{c}{ Stock } & No. of shares \\
\hline KenGen & $2,198,361,344$ & Co-op Bank & $4,889,316,295$ \\
KPLC & $1,951,467,045$ & Equity Bank & $3,702,777,020$ \\
E.A. P.C & $90,000,000$ & NIC & $639,945,603$ \\
KenolKobil & $1,471,761,200$ & HFCK & $352,416,667$ \\
DTB & $242,110,105$ & KCB & $2,984,227,692$ \\
NMG & $188,542,286$ & Safaricom & $40,065,428,000$ \\
Kenya Re & $699,949,068$ & Scangroup & $378,865,102$ \\
Unga & $75,708,872$ & BBK & $5,431,536,000$ \\
ARM & $495,275,000$ & Centum & $665,441,775$ \\
\hline
\end{tabular}

Source: author

Table 8. Portfolio Returns

\begin{tabular}{|c|c|c|c|c|c|c|c|c|c|c|c|}
\hline \multirow[b]{2}{*}{$\begin{array}{l}\text { Portfolio } \\
\text { Apr }\end{array}$} & \multicolumn{4}{|c|}{2014} & \multicolumn{7}{|c|}{2015} \\
\hline & $\begin{array}{c}\text { Jun } \\
\text { May }\end{array}$ & Jul & Aug & Sep & Oct & & Nov & Dec & Jan & Feb & Mar \\
\hline $\begin{array}{l}\text { One } \\
-0.0186\end{array}$ & $\begin{array}{l}-0.004 \\
-0.0727\end{array}$ & -0.074 & 0.140 & -0.037 & 0.05 & & 0.004 & -0.0598 & 0.021 & 0.1518 & -0.0717 \\
\hline $\begin{array}{l}\text { Two } \\
-0.0297\end{array}$ & $\begin{array}{c}0.0124 \\
-0.047\end{array}$ & 0.0178 & 0.0685 & -0.0006 & -0.039 & & .0050 & -0.0111 & -0.0251 & 0.0680 & -0.0431 \\
\hline $\begin{array}{l}\text { Three } \\
-0.0704\end{array}$ & -0.0152 & -0.0137 & 0.0559 & 0.0178 & -0.0501 & 0.0888 & 0.016 & 0.0088 & 0.1042 & 0.0520 & 0.0093 \\
\hline
\end{tabular}

Source: author

The portfolio returns in table 6above were then regressed against the market returns, in order to obtain the portfolio betas. The portfolio betas from this regression are captured in table 9 below:

Table 9. Portfolio Betas

\begin{tabular}{llll}
\hline Portfolio & Slope $(\boldsymbol{\beta})$ & Y Intercept $(\boldsymbol{\alpha})$ & P-value \\
\hline One & 0.597 & 0.006 & 0.04 \\
Two & 0.805 & 0.008 & 0.002 \\
Three & 0.826 & -0.002 & 0.001 \\
\hline
\end{tabular}

Source: author

As table 9 above shows, all the findings are significant (p-value $<0.05$ for all findings). Finally, month-by-month cross-sectional regressions of the portfolio returns and betas were then run, using portfolio returns for the period May 2015-April 2016 (table a0 below) and the portfolio betas estimated in the previous step. 
Table 10. Portfolio Betas

\begin{tabular}{|c|c|c|c|c|c|c|c|c|c|c|}
\hline \multirow[b]{2}{*}{$\begin{array}{l}\text { Portfolio } \\
\text { Apr }\end{array}$} & \multicolumn{4}{|c|}{2015} & \multicolumn{6}{|c|}{2016} \\
\hline & $\begin{array}{c}\text { Jun } \\
\text { May }\end{array}$ & Jul & Aug & Sep & Oct & Nov & Dec & Jan & Feb & Mar \\
\hline $\begin{array}{l}\text { One } \\
0.0474\end{array}$ & $\begin{array}{c}0.0433 \\
-0.0711\end{array}$ & -0.0901 & -0.0206 & 0.0290 & -0.0107 & -0.0850 & 0.0180 & -0.1104 & 0.0825 & 0.0449 \\
\hline $\begin{array}{l}\text { Two } \\
-0.0158\end{array}$ & $\begin{array}{l}0.031 \\
-0.0371\end{array}$ & -0.1177 & -0.0866 & 0.0171 & -0.0687 & 0.0893 & 0.0109 & -0.0958 & 0.0283 & -0.0998 \\
\hline $\begin{array}{l}\text { Three } \\
0.0019\end{array}$ & $\begin{array}{c}0.0264 \\
0.0041\end{array}$ & -0.1227 & -0.0140 & 0.0544 & -0.0638 & 0.0702 & 0.0398 & -0.0731 & 0.0669 & 0.0511 \\
\hline
\end{tabular}

6.4 Cross-Section Regression

The outcomes of the cross-section regression are summarised in table 11 below:

Table 11. Second Pass Regression Outcomes

\begin{tabular}{lccc}
\hline Month & Y intercept & Beta & Std. error \\
\hline June 2015 & 0.084 & -0.983 & .002238354 \\
July 2015 & -0.010 & -0.998 & .001563773 \\
Aug 2015 & 0.042 & -0.350 & .053139724 \\
Sep 2015 & 0.002 & 0.283 & .025854288 \\
Oct 2015 & 0.139 & -0.987 & .007269502 \\
Nov 2015 & -0.527 & 0.983 & .024562807 \\
Dec 2015 & -0.009 & 0.363 & .019830992 \\
Jan 2016 & -0.186 & 0.845 & .014217155 \\
Feb 2016 & 0.168 & -0.663 & .029545725 \\
Mar 2016 & 0.196 & -0.394 & .111033555 \\
Apr 2016 & 0.190 & -0.937 & .016144400 \\
May 2016 & -0.229 & -0.880 & .025345759
\end{tabular}

Source: author

The mean of the time series of all the regression slopes given in table 9 above is found. This mean value is -0.309833333 .

\subsection{Interpretation}

The first objective of the analysis was to evaluate the level of systematic risks for firms listed on the NSE. From the time-series regressions carried out, the beta coefficients of the firms listed on the NSE are given in table 5. From the table, it is evident that all the beta values for all the stocks evaluated are less than 1 . This implies that the securities at the NSE are less volatile than the market, an observation that in turn leads to the conclusion that the stocks are not only low-risk, but also are associated with low returns. Two negative beta stocks (Centum and Trans-Century) are also observed, but the rest is positive beta stocks, implying that their returns vary positively with the performance of the market.

The second objective of the study was to evaluate the levels of rates of returns for firms listed on the NSE. Analysis of the returns shows a steep increase in asset prices in 2013 and 2014. This increase in asset prices was accompanied by an increase in market capitalization for the evaluated firms, as well as a steep rise in the value of the NSE all-share index. However, from March 2015, there is a steep decline in asset prices, a decline that remains sustained to date. This signals the onset of a bear run from February 2015, supplanting the Bull Run that had hitherto been observed. This could account for the low (sometimes negative) returns for the stocks evaluated during the testing period (June 2015-May 2016). Overall, the patterns of the stock and market movements indicate higher returns for both individual stocks and for the market between May 2013 to February 2015, but low returns for both in the subsequent period. 
The third objective was to analyze the relationship between systematic risk and expected returns for firms listed on the NSE. With this objective in mind, the mean value of the time series of the regression slopes of the regression between portfolio systematic risk and returns were found to be -0.309833333 . One of the central conditions for the CAPM to hold is that this mean value must be equal to (or very close to) zero. Secondly, this relationship should be both linear and positive. The beta value of -0.31 fails to satisfy both of these conditions. This means that the beta has no explanatory power over returns. Consequently, given the absence of this equality, the study makes the conclusion that the CAPM is not valid for explaining risk-return relationships at the NSE.

Finally, the study also aimed at evaluating the value of the intercept term for firms listed on the NSE. From the cross-section regression between portfolio beta and returns, the mean value of the $\mathrm{Y}$ intercept is -0.14 . Again, this is not equal to or very close to zero, and therefore, findings for the lack of validity in explaining risk-return relationships at the NSE are also corroborated.

\section{Discussion}

The utility of the CAPM model lies in the beta's ability to predict an asset's risk premium. For this to happen, the beta must not be statistically different from zero. By virtue of finding the beta as having been statistically different from zero, the findings arrived at here support prior empirical studies which found that the CAPM is not a valid model for explaining risk-return relationships. Other conditions which these findings violate include: the hypothesized linear risk-return relationship, and the hypothesized zero value for the intercept. Among the empirical studies supported by the findings of this study are the studies of Okumu \& Onyuma (2015) and Fama\& French (2004).

Some of the failures of the CAPM can be attributed to its theoretical failings, and specifically, its many simplifying assumptions, which do not hold in the real world. These include the assumptions of investor rationality, homogeneous investor expectations, zero transaction costs, unrestricted risk-free borrowing, and complete information.

\section{Limitations and Directions for Future Studies}

Although this study addresses the methodological weaknesses of prior studies by basing analysis on portfolios rather than individual stocks (thus correcting measurement error problems) and carrying out month-by-month cross-section regression (thus correcting residual errors); the methodology adopted still fails to account for anomalies in asset pricing. As such, future studies should consider adopting methodologies which account for asset pricing anomalies such as value effects, size effects, momentum effects, and reversal effects.

Although this study initially sought to evaluate all the assets trading on the NSE, a majority of those assets were excluded based on the fact that their prices and returns reflected a non-normal distribution. Future studies should consider expanding the number of firms to study by either transforming the data of the excluded firms or running non-parametric tests for the cohort of excluded firms, and including them in the analysis. Moreover, this study focuses on a three-year period. Future studies can achieve better data fit by using more observations, which can be achieved by using longer study periods.

\section{References}

Baker, H.K. \& Riddick, L.A. (2013). International Finance: A Survey. Oxford: Oxford University Press.

Bhala, K.T., Yeh, W. \& Bhala, R. (2016). International Investment Management: Theory, Ethics and Practice. London: Routledge.

Brigham, E. \& Houston, J. (2015). Fundamentals of Financial Management. Boston, MA: Cengage Learning.

Coffie, W. \& Chukwulobelu, O. (2013). The Cost of Equity Capital in Emerging Market - The Case of Kenya. GSTF Journal on Business Review (GBR), 2(4), 192-199. https://doi.org/10.5176/2010-4804_2.4.270

De Long, J.D., Shleifer, A., Summers, L.H. \& Waldman, R.J. (1990). Noise Trader Risk in Financial Markets. The Journal of Political Economy, 98(4), 703-738. https://doi.org/10.1086/261703

Elbannan, M.A. (2015). The Capital Asset Pricing Model: An Overview of the Theory. International Journal of Economics and Finance, 7(1), 216-228. https://doi.org/10.5539/ijef.v7n1p216

Fama, E. \& French, K. (2004). The Capital Asset Pricing Model: Theory and Evidence. Journal of Economic Perspectives, 18(3), 3-24. https://doi.org/10.1257/0895330042162430

Hearn, B. \& Piesse, J. (2009). An Augmented Capital Asset Pricing Model: Liquidity and Stock Size in African Emerging Financial Markets. African Journal of Finance, SP, 27-57. 
Heshmat, N.A. (2012). Analysis of the Capital Asset Pricing Model in the Saudi Stock Market. International Journal of Management, 29(2), 504.

Köseoğlu, S.D. \& Mercangöz, B.A. (2013). Testing the Validity of Standard and Zero Beta Capital Asset Pricing Model in Istanbul Stock Exchange. Int. J. Bus. Humanit. Technol., 3, 58-67.

Lintner, J. (1965). The Valuation of Risk Assets and the Selection of Risky Investments in Stock Portfolios and Capital Budgets. Review of Economics and Statistics, 47(1), 13-37. https://doi.org/10.2307/1924119

Maitah, M., Khudoykulov, K., Amonov, K. \& Burkhanov, U. (2015). Verifying Capital Asset Pricing Model in Greek Capital Market. Asian Social Science, 11(16), 55-63. https://doi.org/10.5539/ass.v11n16p55

Markowitz, H.M. (2005). Market Efficiency: A Theoretical Distinction and So What? Financial Analysts Journal, 61(5), 17-30. https://doi.org/10.2469/faj.v61.n5.2752

NSE. (2016). Official Website [online]. Available at: https://www.nse.co.ke/ (Accessed 15 May 2016).

Nyangara, M., Nyangara, D., Ndlovu, G. \&Tyavambiza, T. (2016). An Empirical Test of the Validity of the Capital Asset Pricing Model on the Zimbabwe Stock Exchange. International Journal Of Economics And Financial Issues, 6(2).

Okumu, A.N. \& Onyuma, S.O. (2015). Testing Applicability of Capital Asset Pricing Model in the Kenyan Securities Market. European Journal of Business and Management, 7(26), 126-135.

Pamane, K. \&Vikpossi, A.E. (2014). An Analysis of the Relationship between Risk and Expected Return in the BRVM Stock Exchange: Test of the CAPM. Research in World Economy, 5(1). https://doi.org/10.5430/rwe.v5n1p13

Sharifzadeh, M. (2010). An Empirical and Theoretical Analysis of Capital Asset Pricing Model. Boca Raton, FL: Dissertation.

Sharpe, W.F. (1964). Capital Asset Prices: A Theory of Market Equilibrium under Conditions of Risk. Journal of Finance, 19(3), 425-42. https://doi.org/10.1111/j.1540-6261 